\title{
A experiência no ensino de história voltado ao vestibular: um diálogo em torno da construção do conhecimento em um projeto de extensão na cidade do Rio Grande/RS
}

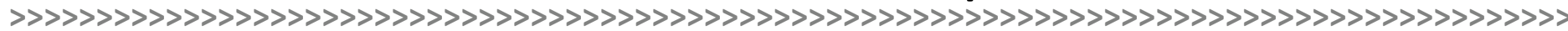

Diego Mendes Cipriano* Carlos Roberto da Silva Machado**

\section{Resumo:}

O objetivo do trabalho é discutir, na perspectiva de dois educadores, em que medida foi possível, num projeto de ensino/extensão que privilegia a "memorização de conteúdos", a construção de um conhecimento histórico para a vida em sociedade, nas atividades do curso preparatório ao vestibular "Grupo de Estudos Paidéia", da Universidade Federal do Rio Grande (FURG). Para tanto, relatamos os antecedentes desta proposta de ensino e o aprimoramento de seus pressupostos didático-pedagógicos, situando a visão de História que procuramos imprimir em nossas atividades educativas. Também, discutimos os aspectos fundamentais dos resultados expressos em diagnóstico que realizamos junto aos educandos, com o fim de verificar as concepções dos mesmos sobre o processo de ensino-aprendizagem e a idéia de História que expressaram na sondagem, tendo em vista verificar as implicações destas percepções frente à metodologia que propusemos.

\section{Palavras-chave:}

Ensino de História. Vestibular. Conhecimento.

\begin{abstract}
:
The aim of this work is to discuss, in the point of view of two educators, a teaching and extension project that favorise the "memorizing of content" instead of construct a historical knowledge for life in society, in the activities of a preparatory vestibular course - "Grupo de Estudos Paideia”, of Universidade Federal do Rio Grande (FURG). Therefore, the authors describe the antecedts of this teaching proposal and the improvement of the pedagogical assumptions, by the historical vision that they try to print in the educational activities that they developed. The fundamental aspects of the results expressed by the students, in order to verify their conceptions of teaching and learning process and the idea of History that they expressed, is also discussed, in order to ascertain the implications of these perceptions by the methodology the authors had proposed.
\end{abstract}

\section{Keywords:}

Teaching History. Vestibular. Knowledge.

\section{As origens da proposta: antecedentes e objetivos}

A construção de projetos voltados ao acesso e à inserção no processo educacional vem sendo desenvolvida por diversas organizações não governamentais, universidades e
* > Mestre em Educação Ambiental pela Universidade Federal do Rio Grande (FURG). E-mail: diego.cipriano2012@gmail.com

* > Doutor em Educação pela Universidade do Rio Grande do Sul (UFRGS). Professor de Políticas Públicas de Educação da Universidade Federal do Rio Grande (FURG).E-mail: karlmac@ig.com.br 
outras instituições. Cursos gratuitos como o Práxis, na cidade de Santa Maria, e Desafio, Pelotas, caracterizaram-se por preparar candidatos ao vestibular nas respectivas cidades.

Sendo assim com o objetivo de congregar os projetos supramencionados e esperando melhorar a infraestrutura pré-existente em cada um deles, otimizando cada vez mais os objetivos que almejamos, teve início, no dia 14 de maio de 2007, o Programa de Auxílio ao Ingresso nos Ensinos Técnico e Superior (PAIETS). O programa passou a agregar as açõe desses projetos, no sentido de organizar estratégias de ensino-aprendizagem ao preparo aos processos seletivos sem perder de vista a orientação ao exercício do protagonismo, da criatividade e da cidadania ativa na condução das atividades educativas.

Em junho de 2007, com este programa, participamos de um edital do Ministério da Educação do Brasil e fomos contemplados com recursos públicos, por meio dos quais começamos a potencializar as ações, a melhorar as condições de atendimento e possibilitar os primeiros passos, no sentido de aperfeiçoar o ensino e as atividades realizadas pelo educadores, junto aos quase 380 alunos dos cursos preparatórios de extensão vinculados ao programa mais amplo.

É dentro deste cenário que se inscreveu um projeto 'piloto' dentro de um dos cursos pertencentes ao supracitado PAIETS, tendo por objetivo não somente contribuir a um 'reforço' às aulas regulares do período noturno, mas proporcionar situações de aprendizagem em História participativas e que exercitasse o senso crítico dos educandos, reunidos desde então num grupo numericamente reduzido e propício a um trabalho mais focalizado.

Foi assim que os chamados minicursos de História, sob nossa responsabilidade direta, iniciaram-se em 2005 no Curso Pré-Vestibular Utopia, projeto precursor do Grupo de Estudos Paidéial preparatório de extensão ao vestibular para jovens e adultos de baixa renda da cidade do Rio Grande. A História não era a única disciplina que desenvolvia este tipo de iniciativa mas, a nosso ver, tornou-se uma das áreas mais engajadas nesta atividades educativas. No início, apenas repassávamos os conteúdos já trabalhados no 'aulōes', no sentido de 'treinar' os estudantes no aprendizado das matérias e na resolução de exercícios. Mas neste segundo semestre de 2008, operamos uma mudança na metodologia dos trabalhos, no sentido de aumentar a participação dos estudantes na construcãao do conhecimento, numa perspectiva de solidariedade e cooperação, entendendo o conhecimento histórico enquanto conhecimento das sociedades humanas no tempo, através do qual se torna possível a transformação da realidade. Também, somente agora tivemos a preocupação de registrar esta experiência, visando publicizá-la à comunidade acadêmica conferir visibilidade ao trabalho realizado por voluntários e estudantes de baixa renda nestes espaços educativos da cidade ${ }^{3}$.

O minicurso de História, expansão do Grupo de Estudos Paidéia, realiza atividades que visam esclarecer dúvidas sobre tópicos de História desenvolvidos no decorrer das aulas do projeto maior. Isto porque, pretendemos auxiliar jovens egressos do ensino básico no estudo e entendimento de matérias requeridas pelo processo seletivo. Mas, além disso, buscamos promover uma mais profunda discussão e troca de conhecimentos entre os participantes, uma vez que educadores e educandos, juntos, constroem o conhecimento. Para nós,

..1 Ensinar nãoétransmitir, pois o ensino depende mais daquele que aprende do que das intenç̄oes, claras ou implíititas, de quem assume o papel de facilitar a experiência do aluno. Ensinar és sobretudo planejar e propor situaçóes de aprendizagem ${ }^{4}$ válidas no contexto sociopsicológico em que elas têm lugar (MARQUES, 1969, p. 1, grifo nosso)

Visamos trabalhar a confiança e a integração de jovens e adultos na aprendizagem dos 'conteúdos' propostos, numa perspectiva dialógica e compartilhada na construção coletiva do conhecimento.
No relacionado à construção do saber histórico, optamos por um fio condutor que considerasse o estudo do passado humano como forma de compreensão dos problema colocados pelo tempo presente, tendo em vista a construção da sociedade que almejamos. Isto porque, a História é um campo do conhecimento que abarca a 'totalidade' da experiência humana nos tempos e espaços, o que nos impele a adotar a definição de História proposta por Selva Guimarães Fonseca:

Concebemos história como o estudo da experiência humana no passado e no presente. A história busca compreender as diversas maneiras como homens e mulheres viveram pensaram suas vidas e a de suas sociedades, através do tempo e do espaço. Ela permite que as experiências sociais sejam vistas como um constante processo de transformacão um processo que assume formas muito diferenciadas e que é produto das açôes dos próprios homens. O estudo da história é fundamental para perceber o movimento e a diversidade, possibilitando comparaçäes entre grupos e sociedades nos diversos tempos e espacos. Por isso, a história ensina a ter respeito pela diferenç $a^{5}$, contribuindo para entendimento do mundo em que vivemos e também do mundo em que gostarímo de viver (FONSECA, 2003, p. 40, grifo nosso).

Tendo em vista esta concepção de História, educadores e educandos poderiam 列 das sociedades humanas pregressas. Com este conhecimento, seria possível uma reflexão crítica da realidade estudada, através de correlacões entre elementos/aspectos de diversas sociedades no tempo. Mas para isso, julgamos necessário adotar o que Flávia Caimi denomina como o "compromisso político" do professor de História, que é

[...] fazer da sala de aula um espaço de construção do conhecimento, de reflexão, de diálogo, de crítica, de participação, de modo que possa exercitar em um ambiente micro as experiências que precisam ser conquistadas coletivamente na vida em sociedade (CAIMI, 2001, p. 151, grifo nosso).

A sala de aula, pois, seria uma espécie de 'amostragem’ da sociedade, um lugar 'estratégico' onde podem ser exercidos práticas/valores necessários à vida social, para a sua eventual transformação pelos seres humanos.

\section{A experiência de 2008: um relato de dois educadores}

Nos estudos deste segundo semestre de 2008, durante três meses de atividades, promovemos seminários sobre temas de História requeridos pelo processo seletivo da FURG 2008-2009 ${ }^{6}$. Visamos, através destes, demonstrar a vinculação da História com o presente, até que os alunos começassem a se interrogar e a procurar por si mesmos tal vinculação (cf. NIDELCOFF, 1991, p. 72).

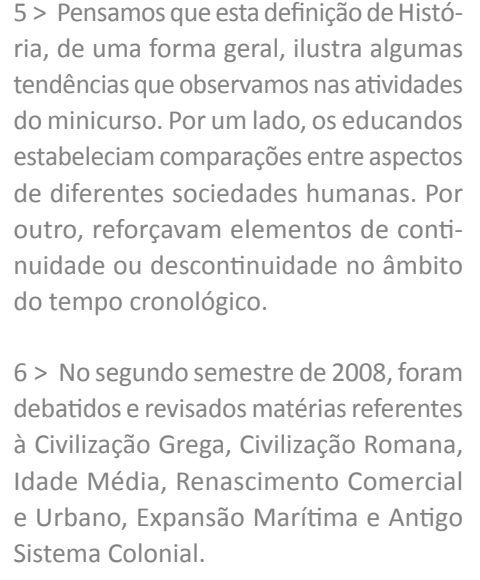




\section{Figura 1 - “Minicurso” de História, 10 out. 2008}

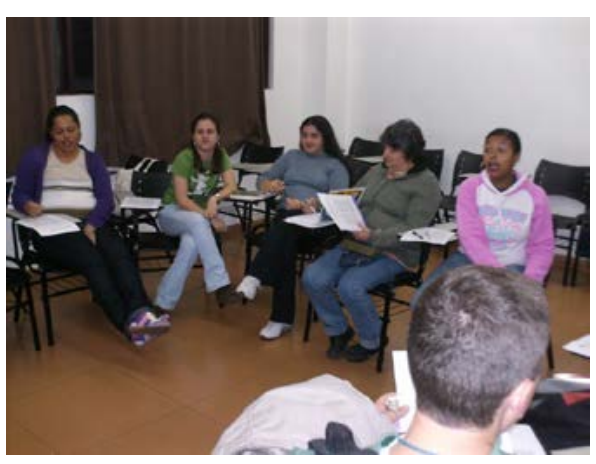

Fonte: Dados da pesquisa, 2008

Em nossos encontros, o debate era utilizado como principal forma de relacionar os assuntos entre si e com a realidade atual. Embora os estudantes procurassem relacionar passado e presente no âmbito da História, ressaltamos que este esforço configurava-se mais como um anseio que os mesmos demonstravam do que um ato deliberado por parte dos educadores nas atividades. Até mesmo porque, segundo Maria Stephanou, o nosso currículo de História dominante é aquele chamado de "programa cronológico", no qual ocorre a organização do conhecimento histórico calcada numa longa duração temporal que visa atestar uma visão oficial dos acontecimentos, valorizando um passado remoto em detrimento do recente por meio da cronologia, sendo esta última a única forma de transmitir as características do processo evolutivo assentado num encadeamento lógico de acontecimentos. Nesta perspectiva, ocorrem repetições recorrentes dos elementos estudados no sentido de uma memorização (BALDISSERA, 1997, p. 58).

Em termos gerais, buscamos exercitar uma reflexão crítica das realidades abordadas, para que os educandos realizassem correlações entre os períodos históricos estudados em seus vários aspectos (social, econômico e cultural) com a sociedade em que vivem. Po vezes, os educandos incorriam em alguns 'anacronismos' eventualmente decorriam de comparações entre épocas e suas sociedades tão distintas, mas que proporcionaram em vários momentos uma análise mais problematizada de cada povo e civilização, resultando em debates intensos sobre as diferentes formações históricas e a natureza de cada uma em analogia com a realidade presente.

A escolha desta abordagem permitiu diversas interpretações dos fatos históricos em seus diversos contextos, para que os educandos pudessem exercitar a realização $d e$ suas escolhas políticas, sociais, econômicas e culturais, e assim, construindo gradativamente uma compreensão de como vivam os homens e mulheres do passado, e de como gostaríamos de viver atualmente com base nestas experiências pretéritas.

Mesmo a discussão sendo mediada pelo uso de um material didático, que sintetizava os principais tópicos de cada matéria, os encontros eram significativamente enriquecidos pela curiosidade investigativa de cada um, em que elaborações esquemáticas voltadas à fixação de conceitos-chave característicos à preparação ao exame de ingresso ao ensino superior, cediam lugar ao protagonismo ativo dos estudantes em compreender as formas de vida de cada sociedade em foco. Com as cadeiras dispostas em círculo, eles podian olhar-se, visando "quebrar o gelo" da aula tradicional, onde todos concentram o olhar em torno do professor. Cada estudante lia um trecho do material didático e, em seguida, comentávamos o assunto que havia sido tratado na etapa da leitura. Assim, outros estudantes também emitiam as suas opiniões sobre os tópicos estudados, debatendo o assunto abordado conosco e com os demais colegas.
Apesar de termos fomentado a construção dialógica do conhecimento histórico sentimos dificuldade em superar o caráter instrumental de um ensino voltado ao Vestibular, direcionamento perceptível desde o Ensino Médio. Para Berenice Corsetti,

Nas escolas de nível médio, em seu dia-a-dia, os professores de História têm sido compelidos a trabalhar duas metas que se mostram quase sempre antagônicas: preparar o aluno para o vestibular ou formar o indivíduo-cidadão (CORSETTI, 1997, p. 48-49, grifo nosso)

Pensamos que estes objetivos antagônicos influenciaram sobremaneira as ativides educativas de nossos minicursos, já que as discussões realizadas pautavam-se na to didá tico voltado às exigências do processo seletivo, o objetivo maior destes estudantes. Todavia, pensamos que esta perspectiva dialógica oportunizou, em certa medida, que educadores e educandos construíssem o seu conhecimento enquanto sujeitos do processo educativo.

Muitas vezes, o ato de 'ensinar' pode ser entendido como sinônimo de 'treinar' ou 'adestrar'. A palavra 'aprender', por sua vez, é comumente entendida como 'ficar sabendo' ou mesmo 'A reter na memória' Todavia pensamos que ensinar seja diferentedisso, sendo una tividade que perpassa a esfera meramente 'conteudista' dos cronogramas de atividades. $\mathrm{O}$ ato de ensinar implica lidar com subjetividades, inquietações e desejos daqueles que aprendem, à medida que a sala de aula é um espaço de sociabilidade e troca de saberes. É preciso considerar que ensinar implica em aprender, na medida em que as duas ações estão intimamente associadas e ocorrem paralelamente. Aliás, elas são interdependentes, já que quem ensina, aprende, e quem aprende, também pode vir a ensinar. Sendo assim, estamos de acordo com Marcos Sandrini quando o mesmo afirma: "Educador e educando são um binômio inseparável. Há momentos em que os educandos se transformam em educadores e há momentos em que os educadores se transformam em educandos." (SANDRINI, 2007, p. 81). Tendo em vista que muitos dos estudantes com que trabalhamos pretendem realizar um curso de licenciatura visando ingressar na carreira de professor/educador, é importante fomentar processos de ensino-apredizagem que os entendam como sujeitos. Isto porque, ao aprender, o educando passa a construir um modelo de docência que poderá praticar em vários momentos de sua vida.

Neste minicurso foi isso o que notamos, já que, em algumas ocasiões, estudantes auxiliavam uns aos outros no aprendizado das matérias que trabalhávamos. É muito significativo mencionar que, no início de uma "aula grande", ao serem perguntados sobre o minicurso que finalizamos, um grupo relatou que era comum, por vezes, algum colega que freqüentava a atividade, auxiliar outros com maiores dificuldades na biblioteca do (a) ser neste sentido que Maria Aparecida Bergamaschi, ao apropriar-se das idéias de Selva Guimarães Fonseca, afirma que o estudante de História deve ser pensado como professor, na associação entre História e Pedagogia, a fim de que possa construir um saber histórico aliado à prática da docência. Isto porque, "[...] é impossível desenvolver uma disciplina de historia sem considerar que esse aluno de historia está aprendendo a historia, mas também está aprendendo uma postura para ensinar-educar." (BERGAMASCHI, 1999, p. 146). Mesmo que neste contexto a autora esteja fazendo alusão aos cursos de formação inicial pensamos que tais idéias nos servem como parâmetros para as atividades de ensino-aprendizagem em História que realizamos. Assim, aqueles que ensinam, aprendem, e aqueles que aprendem, também estão aptos a ensinar. São relações de "ensino-aprendizagem", no sentido da complementaridade de ambas, para além da idéia de que o professor é o emissor de informações a serem 'captadas' pelo estudante, o seu 'receptor'. 
Desse modo, ensinar passa a significar uma troca durante a relação educador-educando. O mesmo acontece com o termo "aprender", já que ambos os indivíduos da relação ensinam e aprendem uns com os outros em uma troca mútua de experiências e conhecimentos. Sendo assim, o aprendizado torna-se um processo de construcão realizado no decorrer das aulas, dos diálogos e interações. É assim que Antonio Carlos Rodrigues, no decorrer das aulas, dos diálogos e interações. É assim que Antonio Carlos Rodrigues,
com base nas concepções de Paulo Freire, situa o diálogo como a essência da "educação libertadora", já que a palavra é condição para que o processo educativo possa ocorrer. De acordo com o autor, sem a dialogicidade, torna-se inviável a construção de um conhecimento libertador capaz de transformar a realidade (RODRIGUES, 2008, p. 58)

Nestas atividades, pudemos identificar, in loco, alguns elementos observados durante o transcorrer do minicurso. Notamos que os estudantes demonstraram "visão processual" da História ${ }^{7}$ e desenvolveram espírito de participação, além de relacionarem tópicos trabalhados com problemas da atualidade. Eles, por vezes, tendiam a ampliar os debates realizados visando socializar, com o pequeno grupo, anseios relacionados à sociedade, à economia e à política atual. Relativamente a este anseio dos estudantes em correlacionar passado e presente nos estudos e discussões, tentativa por vezes endossada por nós, afirmamos que a mesma configura-se enquanto possibilidade à gradativa formação de uma consciência crítica. ${ }^{8}$ Nesta perspectiva, os estudantes sentiram-se instigados a construi o conhecimento histórico ao encontrar, em tempos pretéritos, elementos comparativos/ similaridades com a realidade contemporânea:

Quando tratamos do caráter burocrático e elitista da política de Esparta e da Rom Republicana e Imperial, notamos que, de alguma forma, os estudantes tendem a comparar, anacronicamente9 estas manifestações com a tual política de nosso país. Acreditamos que isso reflete a gestaç̃o de uma consciência cidadã tendo eno vista que os estudantes passam a ver a Histéri não mis como um passa tendo en Vis a da Contemporaneidade (CIPRIANO; RAMOS, 2009, grifo nosso).

Mesmo considerando o caráter embrionário destas analogias estabelecidas com o tempo presente, pensamos que os educandos, ao realizarem paralelos com certas sociedades pretéritas estudadas em sala de aula, conferiam algum sentido ao estudo da História, ao vinculála à possibilidade de se compreender a sociedade em que vivem.

\section{Discutindo a prática: alguns aspectos \\ emergentes}

Ao final de nossas atividades sócio-educativas, realizamos uma breve sondagem para verificar as impressões dos estudantes sobre o trabalho realizado durante os três meses. É neste sentido que elencamos três perguntas básicas aos educandos, na forma discursiva, visando perceber as repercussões das atividades de ensino-aprendizagem desenvolvidas nos minicursos de História. Nesta avaliação, estiveram presentes cinco de uma média de seis estudantes que freqüentaram semanalmente estes espaços educativos. ${ }^{10}$

\section{Figura 2 - Estudantes participam de diagnóstico}

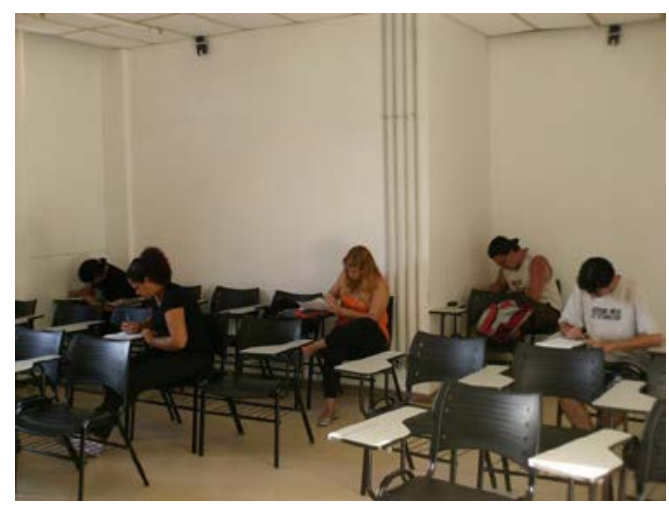

Fonte: Dados da pesquisa, 2008.

Na questão de número 1, solicitamos: "Descreva, em ordem cronológica, os conteúdo trabalhados neste minicurso". Esta questão teve por objetivo verificar se o estudante possuía noção dos assuntos e períodos históricos abordados nestes encontros e, também, se o mesmo apresentava uma noção lógica da seqüência dos períodos estudados. Isto porque, tais percepcões são exigidas pelo exame Vestibular, objetivo último dos educandos que freqüentaram estes espaços educativos. Dos cinco estudantes consultados, apenas um demonstrou uma noção lógica dos períodos históricos estudados e suas fundamentais características intrínsecas. Na resposta, verificamos que um deles fez uso da expressão "História Antiga Clássica", detalhando no seu interior "Grécia" e "Roma". respeito à "Idade Média", situou o "Feudalismo" como parte integrante da mesma. Todavia o restante dos educandos, de maneira geral, tendeu a confundir os períodos históricos com as suas características socioeconômicas. Exemplo disso é a resposta que situa o "Mercantilismo" como sinônimo de "Expansão Marítima e Antigo Sistema Colonial". Outro estudante coloca as cidades antigas de "Atenas" e "Esparta" dissociadas do estudo das civilizações grega e romana.

Na questão de número 2, "O estudo destas matérias despertou o teu interesse para o aprendizado da História? Por quê?”, tencionamos perceber o que motivava os educandos do minicurso a debruçarem-se no estudo da História. Percebemos que esta pergunta acabou por revelar a ideia que os mesmos estudantes tinham em relação à matéria. Dos cinco estudantes que responderam a questão, somente um deles entendeu a História enquanto possibilidade de compreensão do passado para o entendimento do tempo presente e a escolha do futuro almejado: "[...] acho importante compreender o passado para entender $\mathrm{o}$ presente e alcançar os objetivos no futuro [...]”. Os outros estudantes entendem a História apenas como uma oportunidade de conhecer o passado das sociedades humanas. Neste aspecto, cabe citar literalmente uma das afirmações mais marcantes: "[...] assim fiquei conhecendo melhor a História da humanidade [...]".

A questão de número 3, "Sobre o minicurso realizado, destaque a) aspectos positivos eb) aspectos negativos", buscou diagnosticar, de forma sucinta, virtudes e debilidades das atividades sócio-educativas ministradas por nós. Na letra a), dois dos cinco estudantes ressaltaram o cunho participativo e dialógico da metodologia que adotamos durante os minicursos. Neste sentido, é interessante destacar as duas falas: "[...] aulas boas com participação, tanto dos professores como dos alunos [...]" e "[...] o jeito que o conteúdo foi explicado. Sendo discutido entre professor e aluno [...]". No entanto, os outros estudantes tenderam a utilizar termos pertencentes a uma noção de ensino-aprendizagem vinculada às práticas de assimilação e/ou transmissão do conhecimento histórico. Um deles afirmou “[...] aprender nunca é demais, qualquer boa informação é válida. Ter a oportunidade de aprender mais e realmente assimilar é muito importante [...]". Na letra b), quatro estudantes mencionaram a inexistência de "pontos negativos" no trabalho realizado, enquanto que 
um deles observou a necessidade de atividades desta natureza serem realizadas durante todo o ano e em outras áreas do conhecimento no âmbito do projeto maior.

Sendo assim, podemos elencar alguns aspectos importantes das respostas relativas ao diagnóstico. Na questão 1, notamos que as respostas escritas pelos estudantes, relativas à sua percepção da seqüência cronológica dos períodos estudados, nem sempre estão de acordo com as falas presentes nos debates em sala de aula. Nestas discussões, os educando parecem demonstrar um conhecimento básico sobre a periodização histórica, até mesmo relacionando os períodos entre si. Parece-nos que nem sempre as idéias são expressas, na forma escrita, com as palavras que as caracterizam na prática cotidiana. Mas, de forma geral, o diagnóstico demonstrou que a maior parte dos estudantes não possui uma idéia fundamental sobre os períodos históricos, colocando as características ou manifestações sócio-econômicas fundamentais destes períodos como sendo os próprios.

Na questão 2, visualizamos duas noções fundamentais de História, sendo que a mais freqüente a percebe apenas como o conhecimento das sociedades no tempo, enquanto a menos destacada concebe a mesma como forma de conscientização para a eventual mudança da realidade vivida. Acreditamos que as duas concepções diferenciadas de História são frutos das próprias "bagagens" socioculturais pertencentes a cada estudante que freqüentou o minicurso. Sobre a resposta predominante a esta questão, cabe recorrermos ao que diz Maria Stephanou relativamente a alguns aspectos recorrentes de diversos currículos de história. Conforme a autora, um destes aspectos refere-se à ideia de que o conhecimento em história diz respeito ao passado, sendo que o mesmo poderia ser "resgatado" tal como ocorrera, uma vez que os conteúdos históricos trariam em si uma verdade a ser transmitida (cf. STEPHANOU, 1997, p. 56-57). Pensamos que os frequentadores do minicurso, de

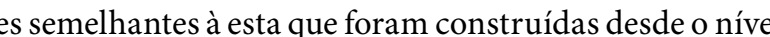
médio de ensino, e por isso as reproduziram no âmbito de nossas atividades educativas e na avaliação final.

Figura 3 - Debate em aula de História do "mincurso", 10 out. 2008

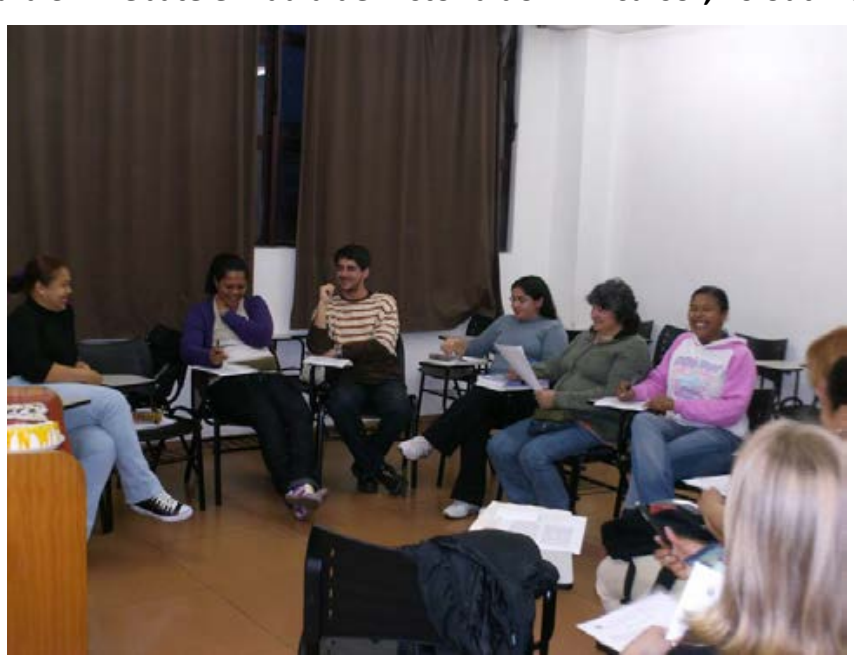

Fonte: Dados da pesquisa, 2008

A questão 3, por sua vez, evidencia que a participação e o diálogo em sala de aula proporcionam motivação à aprendizagem dos estudantes. Já os educandos que percebem, ao menos na forma escrita, o ato de aprender como "assimilação" de um conhecimento externo, talvez não menosprezem a dimensão dialógica na construção do conhecimento histórico, já que se engajaram de forma participativa nas atividades educativas, ainda que tenham feito uso de termos oriundos de uma trajetória escolar tradicional. Para Rodrigo de Azevedo Weimer, um ensino voltado à preparação ao Vestibular não possui o compromisso com uma educação de natureza crítica e de formação, que capacitaria o discente ao exercicio de sua autonomia. Pelo contrario, o ensino direcionado ao Vestibular condiciona o estudante ao treinamento de uma habilidade ou destreza específica. Para o autor, um educador que tenha como objetivo um ensino de caráter formativo, não deveria ser insensível às expectativas trazidas pelos estudantes em relação ao processo seletivo, embora necessite conservar o seu projeto educacional de forma que estas mesmas expectativas não o deturpem (WEIMER, 2002). É neste sentido que procuramos, consoante à preparação ao Vestibular, utilizar uma metodologia de ensino que privilegiasse a construção dialógica do conhecimento histórico, permitindo que os estudantes exercitassem a edificação de um saber não somente para o processo seletivo, mas também à vida em sociedade.

\section{Considerações finais}

A partir das discussões emergentes deste trabalho, e considerando a sondagem/ enquete que realizamos junto aos educandos dos minicursos, é possível destacar alguns pontos a serem discutidos e aprofundados futuramente. Mais do que obter respostas, procuramos levantar questionamentos que podem ser pensados e debatidos por educadores e educandos envolvidos em atividades de ensino-aprendizagem desta natureza. Sendo assim, seguem algumas questões/considerações emergentes da discussão realizada.

No relacionado à noção lógica da cronologia e dos períodos históricos que visamo identificar nos estudantes do minicurso, em que medida esta percepção, que verificamos er 'inexistente' é importante para uma proposta que buscou a construço dialogada 'problematizadora' do conhecimento histórico? Esta nocão 'abstrata' e bem desenhada dos períodos históricos e de suas características fundamentais seriam, em realidade, úteis ao vestibular ou à vida em sociedade? E esperar dos educandos esta percepção não seria uma tentativa de promover e reproduzir a própria assimilação/memorização dos fatos e períodos históricos? Por outro lado, não seria este conhecimento a base sobre a qual se estruturaria o conhecimento em um segundo passo, qual seja, o conhecimento sob um viés crítico?

A noção de História demonstrada pelos educandos, vincula da ̀i deia de um contecimento das sociedades humanas, e não necessariamente ligada a uma expressa possibilidade de transformação social, é realmente um problema de relevância? Em que medida a própria tentativa sistemática, por parte dos educadores, em desenvolver um 'proselitismo' em prol da transformação da realidade, não seria uma tentativa de 'doutrinação' ou 'assimilação' dessa mesma ideia junto aos educandos? A construção efetiva de um conhecimento para a vida em sociedade não estaria assentada justamente nesta autonomia do O próprio conhecimento histórico como um fim em si mesmo não é exigido à aprovação no processo seletivo, interesse último destes estudantes? E este mesmo conhecimento não se constitui enquanto 'etapa' necessária à posterior problematização e transformação da realidade em que vivemos?

Sobre as impressões positivas dos educandos relacionadas à perspectiva dialógica que perseguimos na construção do conhecimento histórico, pensamos que ela esteja em conformidade com a frequência que os mesmos demonstraram nestas atividades educativas. Afinal, realizamos ao todo doze encontros semanais em que estiveram presentes em média cinco estudantes em cada um. Pensamos que o comparecimento nestas atividades se deve em parte ao interesse dos educandos em "revisar" as matérias já trabalhadas em sala de aula, mas também diante da possibilidade que estes vislumbravam no potencial de um trabalho diferenciado em grupo reduzido, com maior participação e envolvimento de todos na construção dialogada e 'problematizadora' do conhecimento histórico. 
Assim, nesta experiência pudemos avançar em vários sentidos na efetivação de uma proposta de construção do conhecimento histórico, mesmo com as limitações com que tivemos de trabalhar ao longo das atividades educativas. Constatamos que foi possível exercitar, ainda que de maneira elementar, uma metodologia que se colocou em direção oposta a alguns pressupostos do preparo ao processo seletivo. Notamos que, de um lado, as atividades situaram-se na intersecção/fronteira entre a construção de um conhecimento para a vida, calcada numa perspectiva de diálogo e protagonismo dos envolvidos no processo educativo, em que a História era vista como possibilidade de compreensão e eventual transformação do mundo pelos seres humanos. E de outro, estas mesmas atividades demonstraram certa permanência dos aspectos instrumentais de um ensino voltado ao Vestibular, através da realização de atividades de fixação/memorização de 'conteúdos', fatos e períodos históricos. Portanto, concluímos que a construção do conhecimento histórico nestes espaços educativos não-formais que visam o preparo ao exame Vestibular, deve ser fruto de constante debate no seio dos processos de ensino-aprendizagem. Nestes espaços, o avanço na construção de um conhecimento 'libertador' e 'para a vida' insere-se, pois, numa perspectiva utópica concreta que necessita ser perseguida por educadores e educandos enquanto uma constituição de longo prazo.

\section{Referências}

BERGAMASCHI, Maria. Será o professor de História um educador? História: debates e tendências, Passo Fundo, v. 1, n. 1, p. 142-146, 1999.

CAIMI, Flávia. Conversas e controvérsias: O ensino de História no Brasil (1980-1998). Passo Fundo: UPF, 2001

CIPRIANO, Diego; RAMOS, Marcelo. A relação entre História e Cidadania discutida sob o olhar de dois educadores. In: MACHADO, Carlos (Org.). Projeto de Auxílio ao Ingresso nos Ensinos Técnico e Superior (PAIETS): das origens à consagração. Rio Grande: EDIGRAF, 2009.

CORSETTI, Berenice. A História e o Vestibular: a experiência da UFSM. In: SEFNER, Fernando; BALDISSERA, José (Org.). Qual história? Qual ensino? Qual cidadania? Porto Alegre: ANPUH, 1997. p. 39-51.

FONSECA, Selva. Didática e prática de ensino de história: experiências, reflexões e aprendizados. Campinas: Papirus, 2003.

MARQUES, Juracy. Ensinar não é transmitir. Porto Alegre: Editora Globo, 1969.

MELLO, Marco (Org.). Paulo Freire e a Educação Popular. Porto Alegre: IPPOA; ATEMPA, 2008.

NIDELCOFF, Maria. A escola e a compreensão da realidade. São Paulo: Brasiliense, 1991.

SANDRINI, Marcos. Para sempre!: o compromisso ético do educador. Petrópolis: Vozes, 2007.

STEPHANOU, Maria. Currículos de História: produzindo concepções de si e do mundo. In: SEFNER, Fernando; BALDISSERA, José (Org.). Qual história? Qual ensino? Qual cidadania? Porto Alegre: ANPUH, 1997. p. 55-62.

WEIMER, Rodrigo. Ensino de História e Vestibular: uma reflexão. In: PADRÓS, Enrique (Org.). Ensino de história: formação de professores e cotidiano escolar. Porto Alegre: EST, 2002. p. 201-211. 